Additional services for Cardiology in the Young:

Email alerts: $\underline{\text { Click here }}$

Subscriptions: $\underline{\text { Click here }}$

Commercial reprints: $\underline{\text { Click here }}$

Terms of use : $\underline{\text { Click here }}$

\title{
Transthoracic three-dimensional echocardiography for the assessment of straddling tricuspid or mitral valves
}

Michael Vogel, Siew Yen Ho, Christopher Lincoln and Robert H. Anderson

Cardiology in the Young / Volume 10 / Issue 06 / November 2000, pp 603 - 609

DOI: 10.1017/S104795110000888X, Published online: 19 August 2008

Link to this article: http://journals.cambridge.org/abstract_S104795110000888X

How to cite this article:

Michael Vogel, Siew Yen Ho, Christopher Lincoln and Robert H. Anderson (2000). Transthoracic three-dimensional echocardiography for the assessment of straddling tricuspid or mitral valves. Cardiology in the Young,10, pp 603-609 doi:10.1017/S104795110000888X

Request Permissions : $\underline{\text { Click here }}$ 


\title{
Transthoracic three-dimensional echocardiography for the assessment of straddling tricuspid or mitral valves
}

\author{
Michael Vogel, Siew Yen Ho, ${ }^{1}$ Christopher Lincoln, ${ }^{2}$ Robert H. Anderson ${ }^{3}$ \\ GUCH Department, Middlesex Hospital, London; 'National Heart and Lung Institute Imperial College School of Medicine, \\ London; ${ }^{2}$ Royal Brompton Hospital London; ${ }^{3}$ The Cardiac Unit, Institute of Child Health, London, UK
}

\begin{abstract}
Background: The advent of 3D echocardiography has provided a technique which, potentially, could afford significant additional information over conventional cross-sectional echocardiography in the assessment of patients with straddling atrioventricular valves prior to surgical correction. Methods: Eight patients, aged from 1 month to 9.2 years, were examined with 3D echocardiography. All but three had discordant ventriculoarterial connections or double outlet right ventricle. Data suitable for reconstruction was acquired with transthoracic scanning. Right and left ventricular volumes were calculated in the 3D dataset. Results: 3D echocardiography proved capable of defining the exact degree of straddling by imaging the proportion of tension apparatus attached to either side of the ventricular septum. It was able also to display the atrioventricular junction "en face", thus permitting identification of the precise site of insertion of the muscular ventricular septum relative to the atrioventricular junction. This made it possible first, to calculate the degree of valvar override, and second, to predict the location of the penetrating atrioventricular bundle. End-diastolic volume of the right ventricle in those with straddling tricuspid valves was 73 (61-83)\% of normal, and, of the left ventricle in those with mitral valvar straddling 71 (40-97)\% of normal. Conclusions: 3D echocardiography can aid in planning the optimal surgical procedure in patients with straddling or overrriding atrioventricular valves, as it provides diagnostic information superior to standard crosssectional techniques. It also allows for exact measurement of the volumes of the respective ventricles.
\end{abstract}

Keywords: 3D echocardiography; cross sectional echocardiography; straddling atrioventricular valves

A N ATRIOVENTRICULAR VALVE STRADDLES WHEN its tension apparatus inserts on both sides of the ventricular septum. ${ }^{1}$ This arrangement, of major surgical significance, ${ }^{2,3}$ may or may not be associated with overrriding of the atrioventricular junction guarded by the straddling valve. ${ }^{1}$ Because of the surgical significance, ${ }^{2}$ exact preoperative diagnosis is mandatory. ${ }^{3}$ In this regard, cross-sectional echocardiography has been shown to provide better information than angiography for diagnosis and characterization of straddling atrioventricular valves. ${ }^{4}$ In this study, we assessed the utility of the recently available new imaging technique of $3 \mathrm{D}$ echocardiog-

Correspondence to: Dr Michacl Vogel, GUCH Department, Middlesex Hospital, Mortimer Street, London W1N 8AA, UK. Tel: +44 2073809468 , Fax +44 207 3809469 , E-mail: drmichaelvogel@ doctors.net uk

Accepted for publication 29 March 2000 raphy ${ }^{5}$ to ascertain if it could improve still further the diagnostic yield. Specifically, we evaluated whether new "cutplanes" could be reconstructed which are not provided by cross-sectional echocardiography, and whether the end-diastolic volumes could accurately be calculated for each of the ventricles.

\section{Methods}

We examined eight patients who on the basis of a previous cross-sectional echocardiographic examination, were thought to have straddling atrioventricular valves. Their median age was 2.4 years, ranging from 10 days to 9.2 years (Table 1). We used a commercially available Vingmed 800 (GE Vingmed Horten, Norway) annular array sector scanner, interfaced with a Tomtec (Tomtec Munich, Germany) computer to generate 3D reconstructions from the cross-sectional images. 
Table 1. Morphology of the heart and great vessels in patients with straddling atrioventricular valves

\begin{tabular}{llll}
\hline Patient & AV Valve Abnormality & $\begin{array}{l}\text { Ventriculoarterial } \\
\text { Connections }\end{array}$ & $\begin{array}{l}\text { Great Vessel } \\
\text { Morphology }\end{array}$ \\
\hline 1 & Tricuspid straddle - with overriding & Concordant & Normal \\
2 & Tricuspid straddle - with overriding & $\begin{array}{l}\text { Pulmonary atresia } \\
\text { Pulmonary atresia }\end{array}$ & \\
3 & Tricuspid overriding - without straddling & Discordant & Subpulmonary stenosis \\
4 & Tricuspid overriding - without straddling & Discordant & Aortic coarctation \\
5 & Tricuspid straddle - with overriding & Double outlet right ventricle & Aortic coarctation \\
6 & Mitral Straddle - without overriding & Double outlet right ventricle & Doubpulmonary and valvar \\
7 & Mitral Straddle - with overriding & & pulmonary stenosis \\
8 & Mitral Straddle - with overriding & & \\
\hline
\end{tabular}

For acquisition of data suitable for reconstruction, we used either fan-like ${ }^{5}$ or rotational scanning ${ }^{6}$ with electrocardiographic and respiratory gating. ${ }^{7}$ The same software is used for reconstruction irrespective of the mode of acquisition of the data. Restless patients were sedated with $70 \mathrm{mg} / \mathrm{kg}$ chloralhydrate. In 3 patients, data was acquired in the catheterization laboratory, where patients in the Royal Brompton Hospital are routinely given general anaesthesia. In 1 patient, data was acquired in the operating room immediately after induction of general anaesthesia. After completion of acquisition of data, we reviewed the acquired cross-sectional slices of the heart. These could then be rotated in any orthogonal plane. When a desired cross-section had been found, the computer began $3 \mathrm{D}$ reconstruction. Three dimensional effects were achieved by assigning different gray-scale values to various 'cardiac structures. ${ }^{8}$ The reconstructed dataset can be dynamically displayed and stored on standard 0.5 inch videotapes. In all the patients with overriding tricuspid and mitral valves, the overall diameter of the valve was determined, together with the parts of the overriding valvar orifice committed to each ventricle. From the dataset, we calculated right and left ventricular volumes using a previously described and validated technique.?

The quantitation is based on a technique of multiple slicing. ${ }^{10}$ Firstly, the longest axis of the respective ventricle is defined in the appropriate cross-section of the dataset. Along the long axis, perpendicular $2 \mathrm{~mm}$ thick slices are displayed on the monitor as cross-sectional images. These are then manually outlined to calculate the area of each slice. The calculated area is multiplied with the thickness of the slice to obtain the volume of each slice. The respective volumes are summed to obtain the volume of the ventricle. Measurements were obtained in end-diastole, and expressed in $\mathrm{mls} / \mathrm{sqm}$ body surface area. According to the literature, the end-diastolic volume of the normal right ventricle is $70 \mathrm{mls} / \mathrm{sqm},{ }^{11}$ and that for the normal left ventricle is $60 \mathrm{mls} / \mathrm{sqm} .{ }^{12}$

\section{Results}

3D reconstruction was possible for all datasets acquired. Reconstruction took between 40 and 240 minutes. All standard views of the heart obtainable with transthoracic conventional cross-sectional echocardiography could be reconstructed, as well as significant new views. Thus, the information obtained by $3 \mathrm{D}$ reconstruction of a conventional four chamber view is similar to that provided by conventional cross-sectional echocardiography (Fig. 1). For the tricuspid valve, this shows the malalignment between the atrial and ventricular septal structures which is the key to diagnosis. In the case of the mitral valve, the reconstructions showed that the valvar leaflets straddled through a defect opening to the outlet components of the right ventricle (Fig.2). In the hearts with override of the left atrioventricular junction, therefore, the atrial and ventricular structures are normally aligned at the crux of the heart. From the conventional cross-sections, we were able to reconstruct "en-face" views of the atrioventricular valves, permitting them to be viewed as seen by the surgeon working from the atrium (Figs 3,4,5). This reveals the fashion in which the valvar leaflets are connnected to the right and left ventricles, respectively (Table 2). While these measurements could not be directly validated at surgery in a nonbeating heart, inspection in the patients subsequently undergoing surgery revealed no differences between the preoperative diagnosis of the extent of straddling and overriding made by $3 \mathrm{D}$ echocardiography and the findings in the operating room.

Volumetry of the ventricles (Table 3) permitted quantitation of the disproportionate sizes of the ventricles compared to hearts with normal atrioventricular junctions. In all 5 patients with 


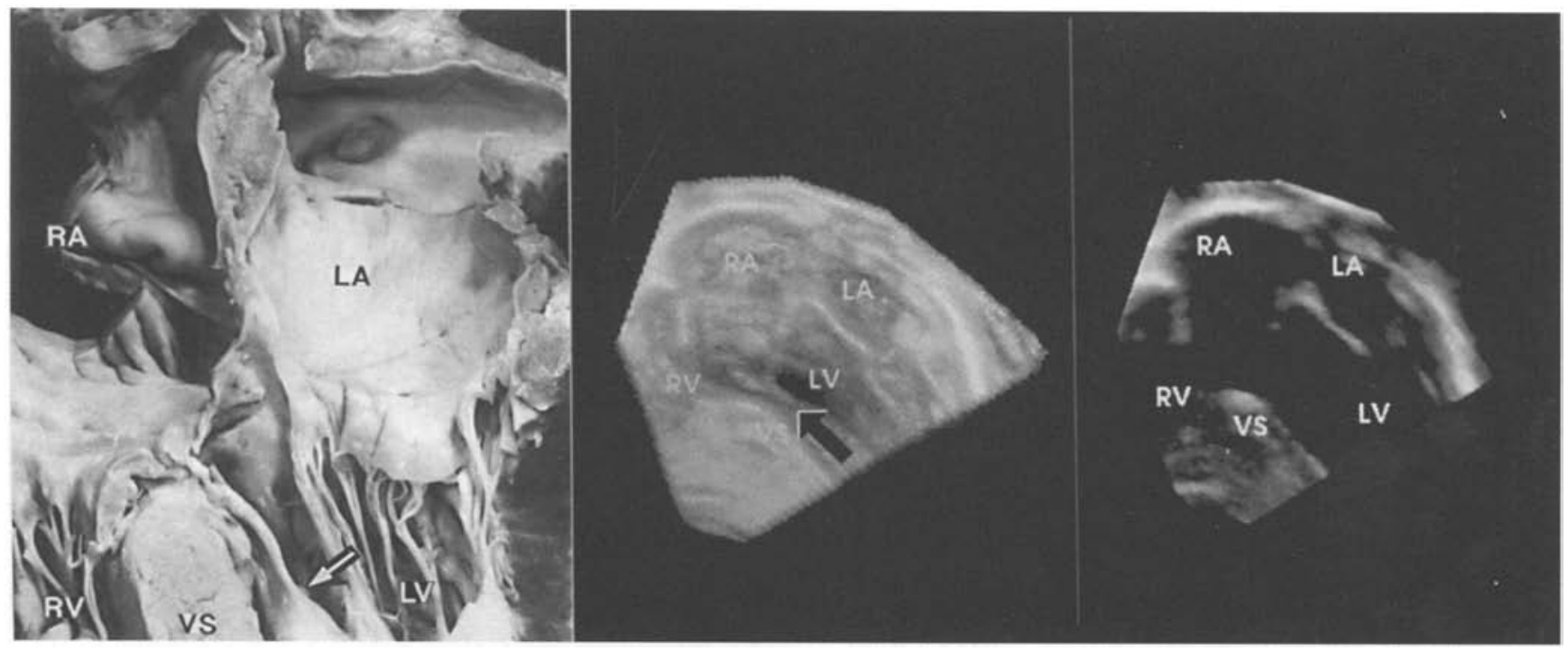

Figure 1.

$3 D$ reconstruction (middle), display of one cross-section of the dataset (right side) in a patient with a concordant ventriculoarterial connections, a ventricular septal defect, and straddling as well as overriding of the tricuspid valve. An anatomic specimen (not from the same patient) is shown on the left. The $3 D$ reconstruction of a conventional 4-chamber view adds little information to the information provided by conventional cross-sectional echocardiography. The arrow in the reconstructed view, and in the specimen, points to the tension apparatus of the tricuspid valve which inserts on left ventricular side of the septum. ( $R A=$ right atrium, $L A=$ left atrium, $V S=$ ventricular septum, $R V=$ right ventricle, $L V=l$ eft ventricle $)$.

straddling of the tricuspid valve, the right ventricle was hypoplastic, with an end-diastolic volume of $73(61-83) \%$ of the expected norm. The left ventricular volume in these 5 patients was $114(107-122) \%$ of normal. The smallest right ventricular volume was measured in a patient with both overriding and straddling of the tricuspid valve. In the 3 patients with straddling of the mitral valve, left ventricular end-diastolic volume was $71(40-97) \%$ of normal, while the right ventricular volume was $118(103-139) \%$ of normal.

\section{Discussion}

Our study has shown that 3D echocardiography can offer important and new information in patients with straddling tricuspid or mitral valves. Specific advantages are, first, the provision of the "en-face" view. This allows for precise determi-

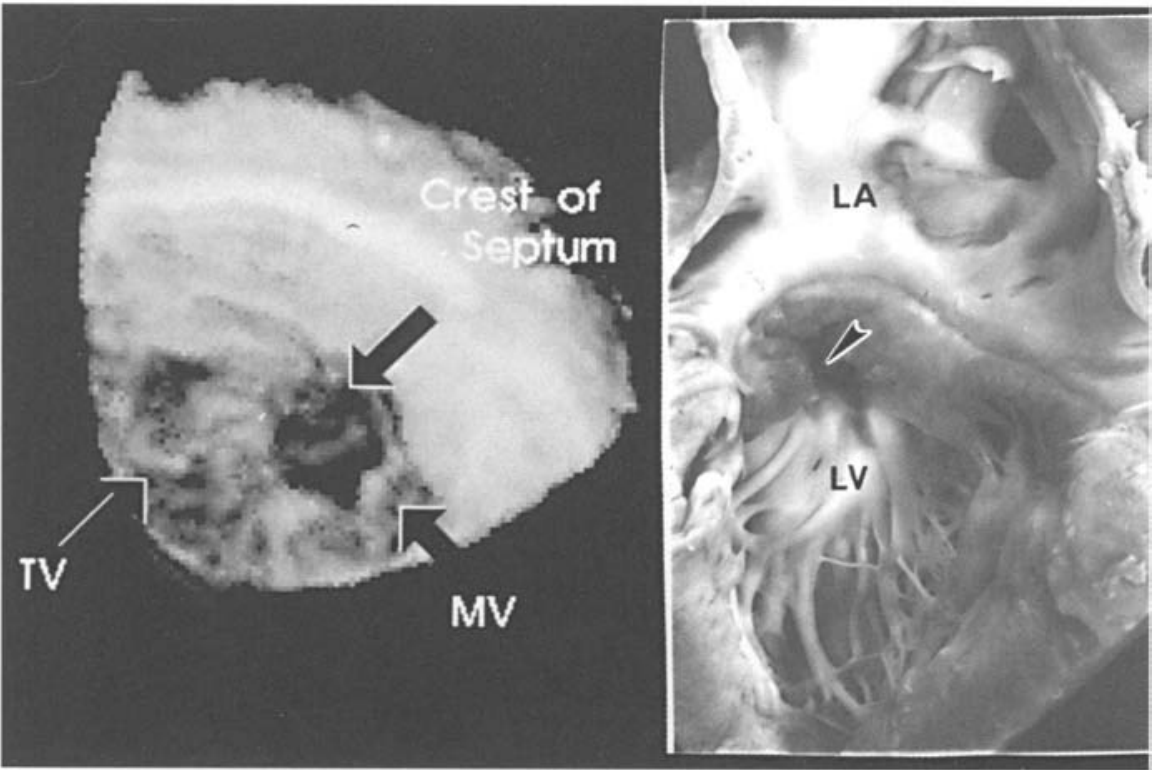

Figure 2.

$3 D$ reconstruction in a patient with double outlet right ventricle and subpulmonary ventricular septal defect (Taussig-Bing beart) complicated by straddling and overriding of the mitral valve. The reconstruction of the "en-face" view (left side) visualizes the crest of the septum (black arrow). On the right side an anatomical specimen (not from the same patient) is shown of a Taussig-Bing malformation with straddling of the mitral valve. The specimen bas been cut in a way such to match the three-dimensional reconstruction, and is seen in a view similar to that obtained by the surgeon during inspection of the mitral valve. (TV=tricuspid valve, $M V=$ mitral valve). 


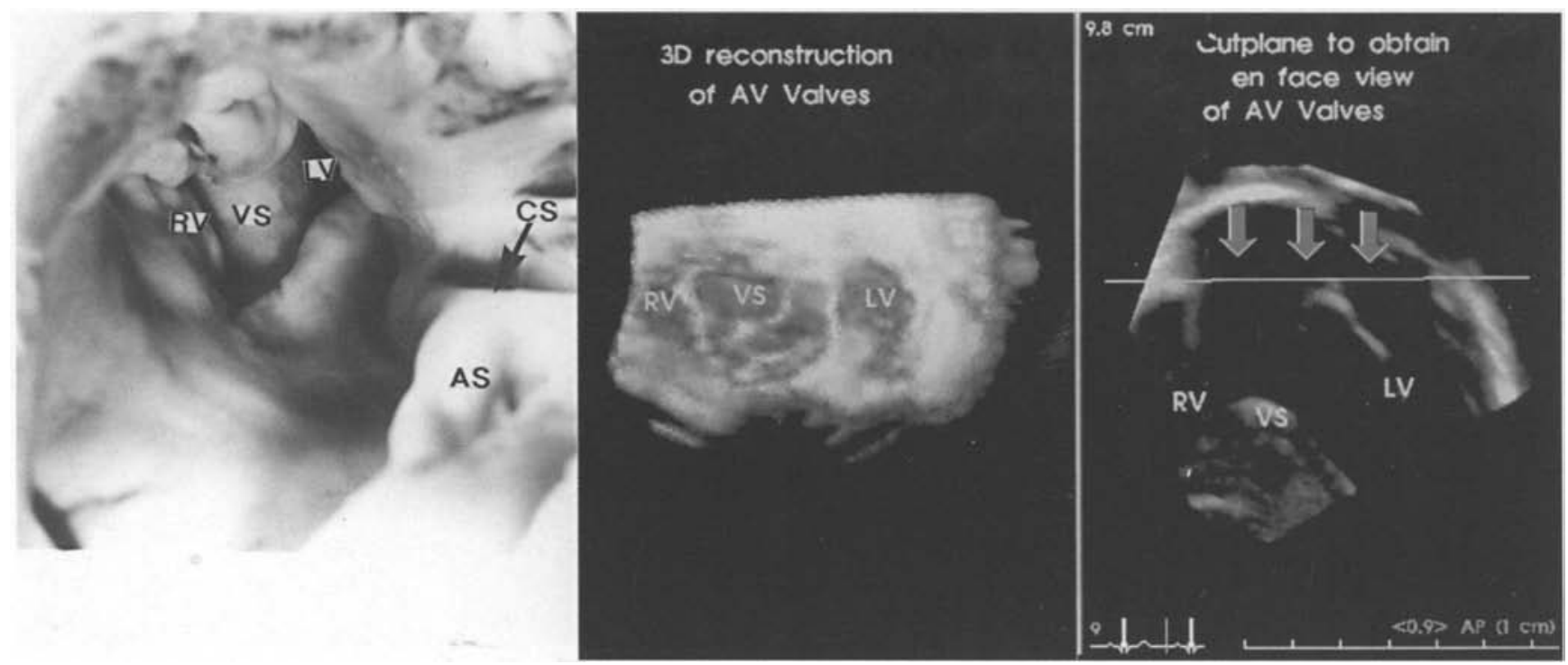

Figure 3.

$3 D$ reconstruction (middle), and display of one cross-section of the dataset (rtght sude) in the same pattent as shown in Figure 1 . The spectmen shown on the left side is not from the same patient. The arrows in the cross-section displayed on the right indicate the position and direction of view of an observer in the atrium looking downwards onto the orifice of the valve to obtain the "en-face" view of the atroventricular junction. The $3 D$ reconstruction of this viewplane illustrates better than the conventzonal four-chamber view the insertion of tricuspid valvar cords in the left ventricle. It also demonstrates the overriding of the valuar orifice. The crest of the ventricular septum is seen, together with the part of the tricuspid valve committed to the left ventricle (VS=ventrucular septum, $R V=$ right ventricle, $L V=$ left ventricle, $A S=$ atrial septum, $C S=$ coronary sinus).

nation of the relationship of the overriding atrioventricular junction to the ventricular septum. Secondly, 3D echocardiography is helpful in measuring accurately ventricular volumes, particularly those of the right ventricle. ${ }^{9}$ This has been difficult using conventional cross-sectional echocardiography. ${ }^{13}$ We have previously validated such volu-

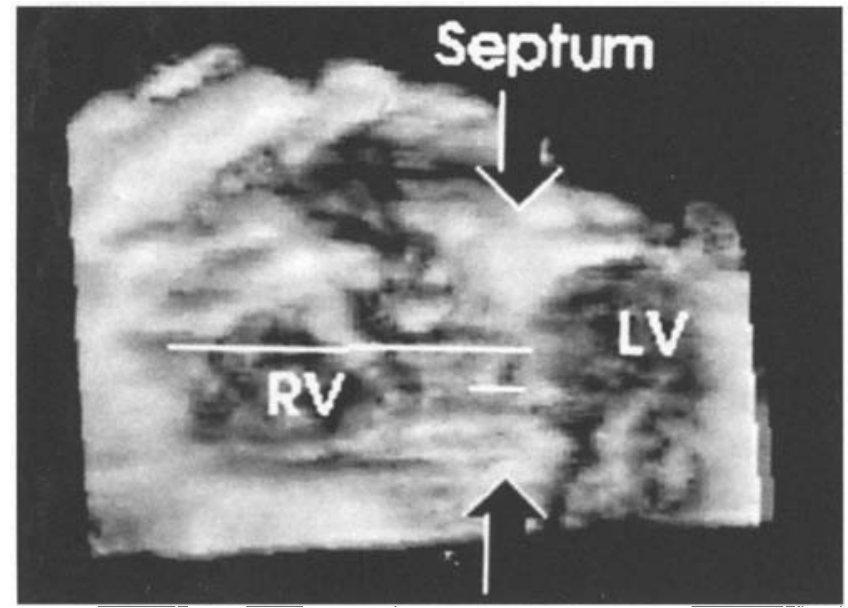

Figure 4.

Reconstruction from the same patient as shown in figures 1 and 3 . In this "en face" view of the atroventricular junction, we have put 2 lines of measurement. The upper line shows the whole tricuspid valve orifice in diastole, the lower short line, the part of the valve which is straddling the ventricular septum. metric measurements using 3D echocardiography in vitro, ${ }^{9}$ and have compared measurements of right ventricular volumes with the "gold standard" of magnetic resonance imaging. ${ }^{14}$

\section{Information on anatomy of straddling}

The key feature in the diagnosis of straddling of the morphologically tricuspid valve is the malalignment between the atrial and ventricular septal structures. ${ }^{1,3}$ This is because the morphologically tricuspid valve straddles and overrides the inlet component of the muscular ventricular septum. The morphologically mitral valve, in contrast, straddles and overrides through an interventricular communication leading to the outlet component of the right ventricle. ${ }^{15}$ When the mitral valve straddles, therefore, the atrial and ventricular septal structures are normally aligned at the crux of the heart. ${ }^{15}$

This information is crucial in predicting the location of the atrioventricular conduction axis. ${ }^{15}$ All that information, of course, can usually be well displayed by conventional cross-sectional scanning. ${ }^{16}$ The important information for the surgeon is the extent of straddling, specifically whether the tendinous cords are attached merely to the septal crest, to the wrong side of the septum, or to the parietal wall of the other ventricle. ${ }^{17-19}$ In addition, the surgeon needs to know the precise 


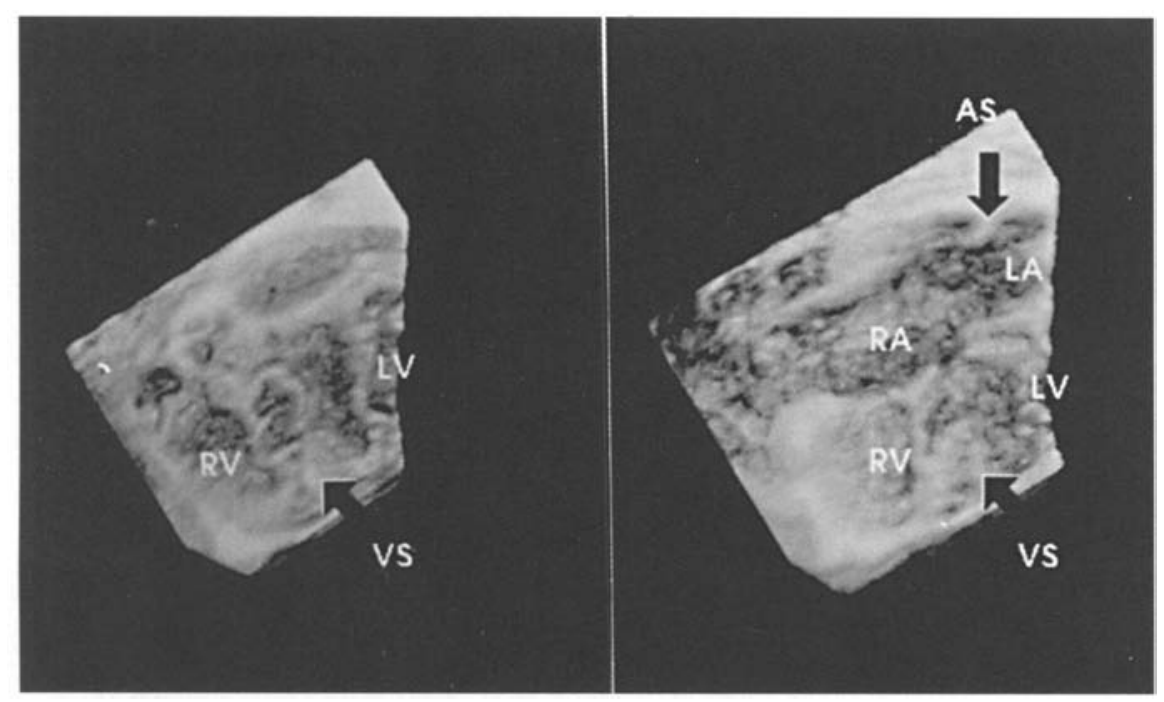

Figure 5.

$3 D$ reconstructions from a patient with concordant atroventricular and discordant ventriculoarterial connections, ventricular septal defect, subpulmonary stenosis, and overriding of the tricuspid valve without straddling of its tension apparatus. On the right side is shown a view similar to the four-chamber cut, while on the left an "en-face" view of the atrioventricular junction is reconstructed. The malalignment between the atrial $(A S)$ and ventricular septum (VS) is well seen. The fact that the tricuspid valve tension apparatus inserts into the right ventricle can be best seen in the "en face" view. ( $R A=$ right atrium, $L A=$ left atrium, $R V=$ right ventricle, $L V=$ left ventricle).

point at which the muscular ventricular septum makes contact with the atrioventricular junction, since this position indicates the location of the atrioventricular conduction axis. Again, these important morphological details have previously been diagnosed accurately by cross-sectional echocardiography, ${ }^{16}$ but $3 \mathrm{D}$ reconstruction offers

Table 2. Measurements of diameter of tricuspid and mitral valve total diameter and segment of diameter overriding the ventricular septum (mms)

\begin{tabular}{lll}
\hline Patient & $\begin{array}{l}\text { Total diameter of } \\
\text { atrioventricular valve }\end{array}$ & $\begin{array}{l}\text { Segment of diameter } \\
\text { of valve committed to } \\
\text { contralateral ventricle }\end{array}$ \\
\hline 1 & 32 & 12 \\
2 & 22 & 4 \\
3 & 24 & 6 \\
4 & 35 & 15 \\
5 & 26 & 5 \\
6 & 20 & 0 \\
7 & 22 & 2 \\
8 & 25 & 7 \\
\hline
\end{tabular}

Table 3. Measurements of right and left ventricular enddiastolic volumes ( $\mathrm{ml} / \mathrm{sqm}$ body surface area)

\begin{tabular}{lll}
\hline Patient & $\begin{array}{l}\text { Right ventricular } \\
\text { volume }\end{array}$ & $\begin{array}{l}\text { Left ventricular } \\
\text { volume }\end{array}$ \\
\hline 1 & 54 & 66 \\
2 & 58 & 64 \\
3 & 43 & 73 \\
4 & 48 & 72 \\
5 & 52 & 68 \\
6 & 72 & 58 \\
7 & 78 & 46 \\
8 & 90 & 24 \\
\hline
\end{tabular}

the additional benefit of displaying the heart in a view which replicates the intraoperative appearance. ${ }^{20}$ Before a decision can be made concerning the most appropriate form of surgical repair, be that biventricular, univentricular, or 1 and $1 / 2$ ventricular, however, information is needed concerning the volume of the ventricle, which is necessarily incomplete because of the overriding atrioventricular junction. ${ }^{19}$

\section{Ventricular volumes in straddling}

The cavitary size of the incomplete and rudimentary ventricle is, in many ways, the crucial piece of information for deciding the optimal surgical repair. While 3D echocardiography can accurately assess ventricular volumes irrespective of their geometric shape, ${ }^{9,10}$ we do not yet know the exact limit of cavitary hypoplasia which precludes biventricular repair. ${ }^{3,19}$ In a previous study of unbalanced atrioventricular septal defects, where similar problems exist in respect to the committment of the atrioventricular orifice to one dominant ventricle, with concomitant underdevelopment of the second ventricle, ${ }^{21}$ we measured ventricular volumes by angiography. In this study, ${ }^{21}$ we could not determine the ventricular size representing the limits of normality. The same holds true for the current investigation. Although by analogy to the data available for repair of unbalanced atrioventricular septal defect, ${ }^{22}$ we might anticipate that a volume of the rudimentary ventricle of fourfifths of normal should be acceptable for biventricular repair, it is not established with certainty whether this holds true for patients with straddling valves and complex anomalies of atrioventricular or ventriculoarterial connections. ${ }^{18,23}$ Only increasing experience will answer this question. 


\section{Limitations of this study}

With the currently available hard- and software, thickening of all the imaged cardiac structures during reconstruction of closely sequential crosssectional slices remains a problem. Thus, valvar leaflets, as well as their tension apparatus, appear thickened. Thickening of the sometimes rather delicate tension apparatus ${ }^{10}$ may lead to overestimation of the amount of atrioventricular tension aparatus located in the wrong ventricle. Because all patients were examined with conventional cross-sectional echocardiography before data suitable for subsequent reconstruction were acquired, we did not perform a double-blind study. We were unable, therefore to evaluate the incremental information of $3 \mathrm{D}$ over conventional cross-sectional echocardiography. With the new equipment of real-time 3D echocardiography such a study may be possible. With our equipment as presently used, nonetheless, it is difficult to blind the person acquiring the dataset to the cross-sectional images visible on the screen of the ultrasonic scanner.

The substantial time still needed to achieve a 3D reconstruction in these complex hearts remains a serious limitation, thus precluding further clinical application of this new imaging technique. It also remains difficult to illustrate the $3 \mathrm{D}$ findings in a two-dimensional format, especially in a still-frame picture. Because of this, we have thus produced moving images which can be viewed on the homepage of the Journal (www.greenwichmedical.co.uk). While advances in soft- and hardware have facilitated acquisition of data, frequently obviating the need for sedation, and have considerably shortened the period required for calculations of volume, ${ }^{24,25}$ the clinical utility of $3 \mathrm{D}$ echocardiography still remains limited, confining the technique to evaluation of patients with complex hearts in whom decision-making is frequently difficult and time-consuming. ${ }^{26}$ Despite these limitations, we have shown that $3 \mathrm{D}$ reconstruction offers important additional information on the morphology and cavitary size of patients with straddling atrioventricular valves. If replicated in the clinical setting, the technique should serve to determine the best options for surgical correction.

\section{Internet Site}

You can dowload a QuickTime ${ }^{\mathrm{TM}}$ movie illustrating the 3D findings. Please access www.greenwichmedical.com and click on "Journals" and "Cardiology in the Young" to view the movie and to read further details.

\section{Acknowledgements}

Michael Vogel was supported by a grant from the European Community, Siew Yen Ho and Robert H. Anderson are supported by the British Heart Foundation, together with the Joseph Levy Foundation.

\section{References}

1. Milo S, Ho SY, Macartney FJ, Wilkınson JL, Becker AE, Gittenberger-de Groot AC, Anderson RH. Straddling and overridıng atrioventricular valves. morphology and classification. Am J Cardiol 1979;44: 1122-1134.

2. Pacifico $A D$, Soto $B$, Bargeron $L M$ |r. Surgical treatment of straddlıng tricuspid valves. Circulation 1979;60: 655-664.

3. Anderson RH. Surgical repair of straddlıng and overriding tricuspid valve.Cardiol Young 1997;7: 122-128.

4. Hagler DJ, Tajik AJ, Seward JB, Marr DD, Ritter DG. Double outlet right ventricle: Wide-angle two-dimensional echocardographic observations. Circulation 1981;63: 419-428

5. Vogel M, Ho SY, Bühlmeyer K, Anderson RH. Assessment of congental heart defects by dynamic three-dimensional echocardiography: Methods of data acquisition and clinical utility. Acta Paediatrıca 1995; Supplement 410: 34-39.

6. Ludomirsky A, Vermillion R, Nesser J, Marx G, Vogel M, Derman R, Pandian N. Transthoracic real-time three-dımensional echocardiography using rotational scanning approach for data-acquisition. Echocardiography 1994,11: 599-606.

7. Vogel M, Lösch S Dynamic three-dimensional echocardiography with a computed imaging probe: Initial clinical experience with transthoracic application in infants and children with congenital heart defects. Br Heart J 1994;71: 462-467.

8. Pandian NG, Roelandt J, Nanda NC, Sugeng L, Cao Q-L, Azevedo J, Schwartz S, Vannan M, Ludomirsky A, Marx G, Vogel M. Dynamic three-dimensional echocardiography: Methods and clinical potential. Echocardıography 1994;11: 237-259.

9. Vogel $\mathbf{M}$, White $\mathrm{P}$, Redington $\mathrm{A}$. In vitro validation of right ventricular volume measurement by $3 \mathrm{D}$ echocardiography. $\mathrm{Br}$ Heart J 1995;74: 460-463.

10. Buck Th, Schón F, Baumgart D, Leischık R, Schappert Th, Kupferwasser I, Meyer J, Görge G, Haude M, Erbel R. Tomographic left ventricular volume determination in the presence of aneurysm by three-dimensıonal echocardiographic imaging. I: asymmetric model hearts. J Am Soc Echocardiogr 1996;9: 488-500.

11. Helbing WA, Rebergen SA, Maliepaard C, Hansen B, Ottenkamp J, Reiber JHC, de Roos A. Quantification of right ventricular function with magnetic resonance imaging in children with normal hearts and with congenital heart disease. Am Heart J 1995;130: 828-837.

12. Graham TP jr, Jarkamani JM, Canent RV, Morrow MN. Left heart volume estimation in infancy and childhood. Circulation $1971 ; 43: 895-904$

13. Helbing WA, Bosch HG, Maliepaard C, Rebergen SA, van der Geest RJ, Hansen B, Ottenkamp J, Reiber JHC, de Roos A Comparison of echocardiographic methods with magnetic resonance imaging for assessment of right ventricular function in children Am J Cardiol 1995;76: 589-594.

14. Vogel M, Gutberlet M, Dittrich S, Hosten N, Lange PE. Comparison of magnetic resonance imaging and $3 \mathrm{D}$ echocardography in the in vivo assessment of RV volume and mass. Heart 1997; 78: 127-130.

15. Wenink AC, Gittenberger-de Groot AC. Straddling mitral and tricuspid valves: morphologic differences and developmental background. Am J Cardiol 1982;49: 1959-1971. 
16. Rice MJ, Seward JB, Edwards WD.Straddlıng atrioventricular valve: two-dimensional echocardiographic diagnosis, classification and surgical implications. Am J Cardiol 1985;55: 506-513.

17. Aziz KU, Paul MH, Muster AJ, Idriss FS. Positional abnormalities of atrioventricular valves in transposition of the great arteries including double outlet right ventricle, atrioventricular valve straddling and malattachment. Am J Cardiol 1979;44: $1135-1145$.

18. Tabry IF, McGoon DC, Danielson GK, Wallace WR, Tajik AJ, Seward JB. Surgical management of straddling atrioventricular valve. J Thorac Cardiovasc Surg 1979;77: 191-201.

19. Reddy VM, Liddicoat JR, McElhınney DB, Brook MM, van Son JAM, Hanley FL. Biventricular repair of lesions with straddling tricuspid valves using techniques of cordal translocation and realignment. Cardiol Young 1997,7: 147-152.

20. Vogel M, Ho SY, Lincoln C, Yacoub MH, Anderson RH. Threedimensional echocardiography can simulate intraoperative visualization of congentally malformed hearts. Ann Thorac Surg 1995;60: 1282-1288

21. Vogel M, Sauer U, Bühlmeyer K, Sebening F. Atrioventricular septal defect complicated by right ventricular outflow tract obstruction. Analysis of risk factors regarding surgical repair. $\mathbf{J}$ Cardiovasc Surg 1989;30: 34-39.
22. Fisher EA, Doshi M, Bubrow JW. Effect of palliative and corrective surgery on ventricular volumes in complete atrioventricular canal. Pediatr Cardiol 1984;5: 159-166.

23. Huhta JC, Edwards WD, Danielson GK, Feldt RH Abnormalities of the tricuspid valve in complete transposition of the great arteries with ventricular septal defect. J Thorac Cardiovasc Surg 1982;83. 569-576.

24. Acar P, Maunoury C, Antonietti T, Bonnet D, Sidı D, Kachaner J. Left ventricular ejection fraction in children measured by three-dimensional echocardiogaphy using a new transthoracic integrated 3D-probe. A comparison with equilibrium radionuclide angiogaphy. Eur Heart J 1998;19: 1583-1588.

25. Ota T, Fleishman CE, Strub M, Stetten G, Ohazama CJ, von Ramm OT, Kısslo J. Real-tıme, three-dimensional echocardiogrphy: Feasibulity of dynamic right ventricular volume measurement with salıne contrast. Am Heart J 1999,137: 958-967.

26. Vogel M, Ho SY, Anderson RH, Redington AN. Transthoracic $3 \mathrm{D}$ echocardiography in the assessment of subaortic stenosis due to a restrictive ventricular septal defect in double inlet left ventricle with discordant ventriculoarterial connections. Cardiol Young 1999; 9: 552-558. 